\title{
KUALIFIKASI SEORANG PENGINJIL MENURUT RASUL PAULUS DAN IMPELEMENTASINYA BAGI PENGINJIL MASA KINI BERDASARKAN KITAB FILIPI 3:7-14
}

\author{
Gerhard Eliasman Sipayung ${ }^{1}$, Rima Tarigan ${ }^{2}$, Riste Tioma Silaen ${ }^{3}$ \\ Sekolah Tinggi Teologi Baptis Medan (STTBM) ${ }^{1,2}$ \\ Sekolah Tinggi Teologi Injili Arastamar Jakarta (SETIA) ${ }^{3}$ \\ gracio111213@gmail.com
}

\begin{abstract}
This study was conducted to obtain an overview of the criteria of an evangelist according to the perspective of Philippians 3:7-14 to add references to the views of the Bible about an evangelist in carrying out his duties and responsibilities in preaching the Gospel to fulfill the great commission and support one of the Church's triduties. This needs to be done to equip evangelists, mission agencies and even theological schools to equip people who will go specifically to the field of evangelism and in general Christians who also have the same responsibility in preaching the gospel. Facts in the field cannot be denied, many things happen in the field in terms of obstacles or problems, even concepts that are not the same in preaching the gospel. The understanding of evangelists and ways of looking at this evangelistic task can have different perspectives, therefore it is necessary to learn from Paul's point of view as an evangelist and apostle who has dedication and determination in the task of preaching the gospel. This study uses a qualitative approach with the method of literature/literature and facts in the field. The results of this study indicate that; first, evangelists must have a visionary perspective, second serve with the concept of grace, third have high accuracy in understanding the concept of Christology, fourth researchers are consistent with the orientation of the heavenly calling.
\end{abstract}

Keywords : Evangelist, Apostle Paul, The Bookf Philipians

\begin{abstract}
Abstrak
Penelitian ini dilakukan untuk memperoleh gambaran kriteria seorang penginjil menurut perspektif kitab Filipi 3:7-14 dan tak kalah pentingmenambah referensi pandangan-pandangan Alkitab tentang seorang penginjil dalam melaksanakan tugas dan tanggungjawab dalam pemberitaan Injil untuk menggenapi Amanat Agung dan mendukung salah satu tritugas Gereja.Hal ini perlu dilakukan untuk memperlengkapi para penginjil, badan misi bahkansekolah teologi memperlengkapi orang-orang yang akan terjun secara khusus ke ladang penginjilan dan secara umum orang kristen yang juga memiliki tanggungjawab yang sama dalam memberitakan Injil.Fakta dilapangan tidak dapat dipungkiri, banyak hal yang terjadi dilapangan dalam hal kendala atau masalah, bahkan konsep yang tidak sama dalam memberitakan Injil. Pemahaman para penginjil dan cara memandang tugas penginjilan ini dapat memiliki perspektif yang berbeda-beda, oleh karena itu perlu belajar dari sudut pandang Paulus sebagai seorang penginjil dan rasul yang memiliki dedikasi dan keteguhan hati dalam tugas pemberitaan Injil. Penelitian ini menggunakan metode pendekatan kualitatif dengan
\end{abstract}


metode literatur atau pustaka. Hasil dari penelitian ini menunjukkan bahwa; pertama, Penginjil harus memiliki perspektif visioner, kedua Penginjil melayani dengan konsep anugerah, ketiga Penginjil memiliki akurasi yang tinggi memahami konsep Kristologi, keempat Penginjil konsisten kepada orientasi panggilan sorgawi.

Kata Kunci: Penginijl, Rasul Paulus, Kitab Filipi

\section{PENDAHULUAN}

Berbicara mengenai penginjilan adalah hal yang sering dibicarakan dan dilakukan oleh Gereja, karena tanpa penginjilan tidak ada kekristenan, dan tanpa kekeristenan tidak ada perubahan paradigma cara berfikir menurut pandangan Kristen untuk mempengaruhi kehidupan sosial, politik agama, ekonomi dalam masyarakat. Hal ini dibuktikan dengan data statistik bahwa jumlah oang Kristen termasuk katolik masih mencapai sekitar $14 \%$ di Indonesia ${ }^{1}$

Penginjilan dan Injil merupakan suatu kesatuan yang tidak dapat dipisahkan. Injil (euanggelion), diartikan sebagai "kabar atau berita baik", sedangkan penginjilan berarti mendeklarasikan suatu berita yang spesifik dalam hal ini menyatakan pribadi Yesus Kristus itu sendiri, Juruselamat yang hidup dan Tuhan yang memerintah. ${ }^{2}$ Beranjak dari pengertian ini, maka Injil merupakan kabar yang membuat orang yang mendengarkan berita tersebut bersukacita ketika meresponi berita ini, karena dalam berita Injil manusia mendapatkan solusi dalam hal pengampunan dosa yang menjadi persoalan rohani dalam setiap kepercayan yang menyakini bahwa setelah kematian ada penghakiman kepada manusia oleh karena pelanggaran-pelanggaran,etika atau kejahatan-kejahatan yang dilakukan ketika masih hidup dalam bahasa teologinya disebut dosa. Walaupun fakta dilapangan yang mendengarkan berita ini justru banyak menolak bahkan melakukan perlawanan yang keras karena dianggap melawan konsep yang selama ini diyakini dan dipegang sebagai sebuah kebenaran oleh orang yang belum mendengarkan Injil. Dalam mengerjakan pekerjaan pemberitaan Injil semua orang percaya memiliki tanggungjawab yang sama untuk mengerjakan pekerjaan pemberitaan ini karena setiap orang percaya adalah orang-orang yang dipanggil untuk melanjutkan karya penyelamatan melalui Injil. Ketika seseorang melakukan pemberitaan Injil dibutuhkan banyak hal untuk mendukung pekerjaan ini seperti tenaga, dana dan sumber daya dalam pemberitaan Injil.Ketika seorang penginjil mengerjakan pengnjilan maka penginjlan harus dikerjakan sebagai pengabdian diri dan mengandalkan kekuatan Tuhan. Selain memahami bahwa pemberitaan Injil merupakan pengabdian diri, seorang pemberita Injil harus menyadari dengan benar pedoman yang dilakukan dalam pemberitaan Injil, sehingga ketika memberitakan Injil, maka dalam hal perencanaan, teknis, dan juga mobilisasi segala sumber daya tidak salah arah dan tujuan

Hal yang paling penting bagi seorang Penginjil adalah Injil yang diberitakan dalam Yesus Kristus harus bersifat eksklusif.Keeksklusifan ini adalah standard mutlak dalam pemberitaan Injil. Seorang Penginjil harus memegang keeksklusifan Yesus sebagai Juruselamat yang esa karena memiliki hidup dan yang tak

\footnotetext{
${ }^{1}$ BPS, "Penduduk Menurut Wilayah Dan Agama Yang Dianut," Badan Pusat Statistik, last modified 2020, http://sp2010.bps.go.id/index.php/site/.

${ }^{2}$ J.I Packer, Penginjilan Dan Kedaulatan Allah, Terjemahan Helda Siahaan, ed. Hendry Ongkowidjojo (Surabaya: Momentum, 2010), 26.

${ }^{3}$ J.I Packer, "Penginjilan Dan Kedaulatan Allah" (Surabaya: Momentum, 2003).
} 
berkebinasaan. ${ }^{4}$ Mangentang dan Salurante memberikan dasar kasih terhadap orang lain dan menginginkan pemulihan juga terjadi pada mereka yang diinjili. ${ }^{5}$ Inilah yang menjadi inti dan pokok pemberitaan Injil bahwa hanya dalam Tuhan Yesus manusia mengalami keselamatan. Keeksklusifan kekristenan dalam hal konsep keselamatanmemang terkesan arogan dan dianggap merasa paling benar dalam bingkai kebhinekaan, namun dalam hal ini keeksklusifan Yesus sebagai satu-satunya jalan keselamatan manusia adalah hal yang bersifat mutlak dan tidak boleh menjadi abu-abu dalam pemahaman tentang Injil yang akan disampaikan, karena Yesus sendiri yang mengatakannya (Yoh 14:6). Misalnya kaum pluralis yang berpandangan bahwa keselamatan adalah dari dehumanisasi sehingga menterjemahkan Injil sebagai kebutuhan sosial (Social Gospel) kepada konsep keselamatan lahiriah yang bersifat sekarang dan pengganti Injil, dimulai dari menafsirkan ulang mengenai finalitas Yesus sebagai keselamatan dan mempersoalkan jangkauan keselamatan tersebut. ${ }^{6} \mathrm{Kalau}$ dirunut dalam sejarah, pluralis muncul dari gelombang pemikiran yang disebut dengan humanisme yang melahirkan rasionalisme kearah liberalisme yang memunculkan pandangan teologi-teologi yang berbeda-beda yang dipicu oleh pergumulan sehari-hari akibat keberagaman baik secara politik, ekonomi, budaya dan agama. Tujuan penganut pluralisme adalah agar dapat membina hubungan yang baik dalam masyarakat. ${ }^{7}$ Jika penginjil memegang konsep pluralitas dalam konsep keselamatan, maka orang tersebut tidak layak disebut sebagai seorang penginjil (Kis 4:12: Yoh 14:6)

Memberitakan injil adalah menyatakan Yesus Kristus sebagai Anak Allah yang pernah hadir dalam sejarah manusia. ${ }^{\mathbf{8}}$ Alkitab menunjukkan bahwa Yesus menjadi manusiadan hadir dalam sejarah manusia (1 Korintus 15:3-5) dan merupakan fakta sejarah, namun kekristenan selalu diserang dalam setiap perjalann sejarah kekristenan.Serangan ini banyak dilakukan sejak kekristenan ada sampai saat ini,misalnya yang pernah fenomenal di abad ini seperti kelompok Jesus Seminari. Ada juga kelompok dari Mirza Ghulam Ahmad pendiri Islam Ahmadiyah yang mengatakan bahwa Yesus tidak mati saat tergantung di kayu salib tapi dalam keadaan mati suri. ${ }^{9}$ Meskipun banyak orang yang menolak kehadiran Yesus dalam sejarah manusia berhubungan dengan peristiwa-peristiwa di luar nalar manusia dengan mengutarakan semua peristiwa dengan cara berfikir abad ini yang bersifat empiris, ilmiah dan rasional, sebagai orang percaya harus memegang prinsip kebenaran yang dituliskan oleh Alkitab dalam sejarah manusia yaitu Anak Allah berinkarnasi dalam sejarah manusia. Banyak pendeta bahkan teolog mengutarakan sudut pandang dan cara pemberitaan Inji yang berbeda dalam pelayanan yang dikerjakan, sebagai dorongan atas keyakinan Injil adalah kebutuhan semua orang.Karena itu setiap orang (teolog Kristen) harus terus saling

\footnotetext{
${ }^{4}$ Stephen Tong, Hati Yang Terbakar (Momentum, 2007), 529.

${ }^{5}$ Matheus Mangentang and Tony Salurante, "MEMBACA KONSEP KASIH DALAM INJIL YOHANES MENGGUNAKAN LENSA HERMENEUTIK MISIONAL,” Phronesis: Jurnal Teologi dan Misi 4, no. 1 (2021): 7.

${ }^{6}$ Yafet M Paembonan, "Memahami Tantangan Teologi Pluralisme Dan Teologi Pembebasan,” Jurnal Teologi Berita Hidup 2, no. 1 (2019): 53-54.

${ }^{7}$ Binsar Jonathan Pakpahan Jhon Marthin Elizon Damanik, "Membuang Undi Menemukan Pemimpin: Analisis Plus Minus Sistem Undi Pemilihan Pemimpin Dalam Kisah Raja Saul," Jurnal Abdiel IV (2020): 212.

${ }^{8}$ Packer, "Penginjilan Dan Kedaulatan Allah."

${ }^{9}$ Eka Budhi Santosa, "Studi Teologis-Historis Kebangkitan Yesus: Suatu Jawaban Terhadap Isu Makam Talpiot,” Antusias: Jurnal Teologi dan Pelayanan 2, no. 3 (2013): 198.
} 
mempengaruhi dan menopang demi pemberitaan kabar baik. ${ }^{\mathbf{1 0}}$ Istilah pemberitaan Injil sering diucapkan oleh para Pengkhotbah dan juga kaum awam, namun dalam kenyataannya penginjil dan isi pemberitaan Injil tidak sesuai dengan apa yang dituliskan oleh Alkitab. Injil sudah disalahartikan sebagai hal-hal yang berhubungan dengan kesuksesan secara meteri yang mengakibatkan kehidupan penginjil tidak sesuai dengan kriteria yang dituliskan oleh Alkitab dan sudah menyimpang dalam sikap dan perilaku pelayanan yang dikerjakan. Hal ini memang tidak dapat dihindari, namun pada zaman rasul Paulus hal ini juga terjadi, ada yang memberitakan Injil karena perselisihan, dengki, dengan maksud baik atau karena kasih (Filipi 1:15-16).Injil yang diberitakan oleh orang percaya harus merujuk kepada inti pemberitaan yaitu kabar baik bahwa Kristus telah mati untuk orang berdosa, bangkit dan hidup bagi mereka, ${ }^{11}$ yaitu kabar terbaik dari semua kabar di dunia ini. ${ }^{12}$

Dalam memberitakan Injil dasar untuk melakukan tugaspemberitaan Injil ini harus didorong kasih kepada kristus dan mengasihi orang berdosa ${ }^{13}$ bukan hal-hal yang lain yang justru membuat Injil dan penginjilan itu kehilangan arah. Ketika seseorang memberitakan Injil hal ini berkaitan dengan pengabdian dan penyerahan diri seseorang oleh karena iman bukan karena suatu keahlian seseorangdalam mengerjakan pemberitaan Injil, oleh karena itu desakan untuk memberitakan Injil sangat perlu untuk dilakukan oleh karena panggilan yang jelas untuk melakukan pekerjaan ini. Sejarah mencatat, bahwa banyak misionaris-misionaris yang tiba untuk memberitakan Injil kepada suatu suku dan menyelamatkan jiwa-jiwa oleh karena meresponi Injil yang diberitakan, para penginjil ini memiliki beban dan motivasi yang tidak dapat diterima logika manusia secara umum misalnya meninggalkan keluarga bahkan rela meninggalkan segala kemapanan untuk memberitakan Injil karena alasan "kasih" kepada orang-orang yang belum mendengarkan Injil. Dalam pemberitaan Injil terkadang ada pengalaman para penginjil dengan mengatakan bahwa tempat dimana mereka memberitakan Injil suku atau kelompok, ditempat itu belum pernah mendengarkan Injil sama sekali. Banyak jiwa-jiwa yang mati yang tidak terhitung banyaknya sebelum mendengarkan Injil meskipun banyak juga yang menolak Injil ${ }^{14}$ meskipun mereka masih hidup untuk mendengarkan Injil. Sebelum seseorang mati,jiwanya memerlukan Juruselamat untuk keselamatan jiwa orang tersebut. ${ }^{15}$ Oleh karena itu tugas dan panggilan ini hanya bisa dikerjakan oleh karena panggilan dan didorong oleh kasih kepada Tuhan dan kasih kepada manusia.Pemberitaan Injil adalah perintah mendasar dari Kristus kepada orang percaya untuk memberikan hal yang paling dibutuhkan oleh manusia $^{16}$. Dalam tugas pemberitaan Injilkehilangan arah dan motivasi seorang penginjil bisa terjadioleh karena keadaan dilapangan atau motivasi sejak awal. Hal yang sering menjadi skandal dalam tugas pemberitaan Injil dan menjadi berita publik adalah menjadikan pemberitaan Injil untuk proyek mendapatkan dana dan keuntungan dari para donasi pemberita Injil.Tugas dalampemberitaan Injil merupakan tugas yang harus dimaknai untuk menggenapi amanat Agung Tuhan Yesus (Mat 28:18-20). Tugas ini

\footnotetext{
${ }^{10}$ Hasahatan Hutahaean, "Tantangan Teologi Agama-Agama: Suatu Diskursus Model," KURIOS (Jurnal Teologi dan Pendidikan Agama Kristen) 6, no. 2 (2020): 257.

${ }^{11}$ Howard. G. Hendricks, Beritakan Injil Dengan Kasih (Jakarta: BPK Gunung Mulia, 2000), 12.

${ }^{12}$ Dynamic Churches International, Penginjilan Yang Dinamis (Bandung: Kalam Hidup, 2014), 34.

${ }^{13}$ Witness Lee, Memberitakan Injil Dalam Jalan Hayat (Jakarta: Yaperin, 2021), 96.

${ }^{14}$ Charles H. Spurgeon, The Soul Winner (Yogyakarta: Andi, 2008), 215.

${ }^{15}$ Billy Graham, Beritakan Injil, (Bandung: LLB (Lembaga Literature Baptis), 2001), 53.

${ }^{16}$ M David Sills, Panggilan Misi; Menemukan Tempat Anda Dalam Rancangan Allah Bagi Dunia Ini. (Momentum, 2011), 19.
} 
berhubungan dengan sebuah kewajiban dan bukan sebuah pilihanapalagi mendapatkan keuntungan sehingga semua elemen orang percaya atau Gereja harus bekerjasama mengerjakan tugas pelayanan ini.Ketika seseorang memberitakan Injil maka si penginjil harus memaknai apa yang dilakukan Tuhan Yesus dalam misi penyelamatanNya yaitu pemberitaan pribadi Yesus dan melalui Firman-Nya, yaitu penyelamatan dari dosa ${ }^{17}$ bukan hal yang lain.

Memberitakan Injil adalah tanggungjawab semua orang percaya tanpa terkecuali sebagai pernyataan iman kepada Yesus Kristus.Namun kegiatan gerejawi terkadang dianggap merupakan penyataan iman, padahal sesungguhnya penyataan iman harus berakar kepada Kristus. ${ }^{18}$ Sebagian berpendapat bahwa misi penginjilan adalah dengan dibukanya banyak gereja dan jumlah secara kuantitas jemaat bertambah dalam sebuah Gereja. Namun dampak dari pandangan seperti ini kurang banyak berpengaruh dalam kehidupan masyarakat karena pertumbuhan Gereja akibat perpindahanjemaat dan pertumbuhan karena kelahiran biologis, ${ }^{19}$ berbeda dengan orang-orang yang terlahir bukan dari keluarga Kristen, dalam perjalanan kehidupan kekeristenan yang baru banyak yang menjadi orang yang militan dan berani dalam pelayanan dan dalam pemberitaan Injil meskipun banyak menghadapi tantangan yang berat dalam perjalanan iman yang baru sebagai orang kristen.

Dalam pemberitaan Injil yang menjadi teladan seorang Pemberita Injil yang sempurna adalah Yesus yang memberitakan kabar baik dalam hal kerendahan hatiNyabaik dalam penderitaan dan berkekurangan. ${ }^{20}$ Karakter seperti ini membutuhkan proses dan keteguhan dari seorang pemberita Injil. Teladan seorang penginjil telah diberikan Tuhan Yesus agar setiap orang percaya memiliki beban yang sama dalam memberitakan Injil yaitu melayani. Dalam mengerjakan pemberitaan Injil diperlukan kerendahan hati, dan tentu banyak mengalami tantangan dan penderitaan. Kristus telah mengalami banyak penderitaan oleh karena kesaksianNya bahwa Ia adalah Anak Yang Maha Tinggi, ${ }^{21}$ dan hal yang sama juga dialami oleh para penginjil yang memberikan kesaksian dalam pemberitaan Injil bahwa Yesus adalah Anak Allah.Teladan yang berikutnya adalah seorang Penginjil harus rela mengorbankansesuatu untuk pekerjaan pemberitaan Injil. Pengorbanan Yesus di kayu salib adalah bukti Allah yang mengorbankan AnakNya agar melalui AnakNya menjadi jalan kebenaran dan hidup dalam inkarnasi, ${ }^{22}$ maka tidak mengherankan banyak pemberita Injil yang berkorban harta bahkan nyawa dalam tugas pemberitaan Injil agar banyak orang yang belum mendengar dan belum percaya bertemu dengan Allah yang benar yang menjadi manusia untuk keselamatan jiwa orang-orang yang berdosa yang mencari Tuhan melalui agama atau kepercayaan mereka yang lama. Melalui inkarnasi Yesus maka Allah berbicara langsung kepada manusia agar manusia mengenal dan memahami Dia. ${ }^{23}$

\footnotetext{
${ }^{17}$ Graeme Goldworthy, Preaching The Whole Bible As Christian Scripture, (Inggris: IVP, 2003), 84.

${ }^{18}$ Jack Klumpenhower., Kenalkan Yesus Pada Mereka (Surabaya: Momentum, 2014), 60.

${ }^{19}$ Kosma Manurung, "Efektivitas Misi Penginjilan Dalam Meningkatkan Pertumbuhan Gereja," DUNAMIS: Jurnal Teologi dan Pendidikan Kristiani 4, no. 2 (2020): 225-233.

${ }^{20}$ Ajith Fernando, Allah Tritunggal Dan Misi (Jakarta: Yayasan Komunikasi Bina Kasih (YKBK), 2008), 41.

${ }^{21}$ Yesri Talan Waharman, Made Nopen Supriadi, "Kajian Biblika Prinsip Hidup Berpadanan Dengan Injil Kristus Berdasarkan Filipi 1: 27-30," Phronesis: Jurnal teologi dan Misi IV no 1 (2021): 36.

${ }^{22}$ Stimson Hutagalung, Strategi Pelayanan Dan Penginjilan, (Medan: Yayasan Kita Menulis, 2021), 42.

${ }^{23}$ John Stott, Evangelical Truth- A Personal Plea for Unity, Integrity And Faithfullness (London:

Langham Creative Projects, 2012), 53.
} 


\section{METODE PENELITIAN}

Metode penelitian yang dipergunakan dalam penulisan ini adalah dengan metode kualitatif dengan penelusuran literature-literatur, jurnal dan data statistik. Penelitian seperti ini disebut dengan penelitian literature. ${ }^{24}$ Penelitian ini beranjak dari teori yang diakui keberadaannya yang disusun dalam suatu riset berdasarkan data yang ada. Dalam Jurnal yang ditulis oleh Erna Magdalena dan Alfons Renaldo Tampenawas mereka menulis dari sudut pandang memberitakan Injil sebagai suatu panggilan hamba Tuhan dalam perspektif kisah para rasul $16: 4-10^{26}$, dalam penelitian ini Peneliti meneliti kualifikasi seorang Penginjil berdasarkan Filipi 3:7-14.

\section{HASIL DAN PEMBAHASAN}

Latar penulisan kitab Filipi diperkirakan ditulis pada tahun 62-63 M, secara umum tujuan penulisan kitab Filipi ini adalah agar orang percaya menjadikan Kristus sebagai pusat hidup yang kekal. Kitab Filipi dituliskan oleh Paulus ketika berada dalam penjara kepada Jemaat yang ada di Filipi, kitab ini bersifat pribadi dan penuh kasih untuk menyatakan hubungan antara Paulus dan Jemaat di Filipi, Kristologi, menyajikan standard hidup orang Kristen agar senantiasa bersukacita dalam segala hal dalam tugas pemberitaan Injil dan dalam penderitaan sebagai orang percaya. ${ }^{27}$

\section{Memiliki Perspektif Visioner (7-8)}

Dalam perjalanan kehidupan Paulus, tidak mudah melepaskan semua kebanggaan yang pernah didapatkan oleh Paulus dan tidak memungkiri kenyataan tersebut dan membanggakan prestasi masa lalu dalam bidang keagamaan. ${ }^{28}$ Kata

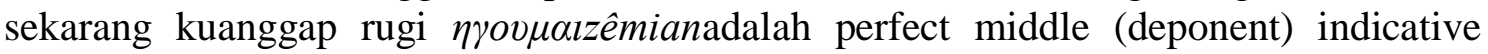
adalah istilah bisnis untuk "kerugian denda." Ayat (8) Malahan segala sesuatu kuanggap rugi" dalam bentuk aorist passive indicative menunjuk pada prestasi, keagamaan, keluarga, warisan, kerabian Paulus sebelumnya dianggap berharga tiba-tiba semua nilainya menjadi hilang. ${ }^{29}$ Paulus melihat bagaimana ritual dan aturan yang tak berguna menjadi sarana untuk memperoleh dan mempertahankan kebenaran sejati, hal ini menjadi pergeseran penekanan teologis utama dari pelatihan agama dan gaya hidup Paulus sebelumnya yang terjadi di pertobatannya di perjalanan ke Damaskus (Kis $9: 1$ 22).

Kemampuan yang dimiliki oleh Paulus setelah bertemu dengan Kristus membuat Paulus menjadi pribadi yang berubah dalam konsep teologis dan cara hidup.Sebelum Paulus menjadi orang Kristen, Paulus seorang yang sangat cerdas di kalangan orang Farisi, kemampuan yang dimiliki oleh Paulus adalah kemampuan berargumen secara

\footnotetext{
${ }^{24}$ Amir Hamzah, Metode Penelitian Kepustakaan, Revisi. (Malang: Literasi Nusantara, 2020), 25.

${ }^{25}$ Yanuar Ikbar, Metode Penelitian Sosial Kualitatif (Bandung: Refika Aditama, 2014).

${ }^{26}$ Erna Magdalena and Alfons Renaldo Tampenawas, "Memberitakan Injil Sebagai Suatu Panggilan

Hamba Tuhan Dalam Perspektif Kisah Para Rasul 16:4-10," XAIRETE: Jurnal Teologi dan Pendidikan Kristiani 1, no. 1 (2021): 52-64, http://e-journal.sttkai.ac.id/index.php/xairete/index.

${ }^{27}$ Grace Maya Panggua, "Hidup Dan Mati Studi Eksegetis Mengenai Maksud Perkataan Paulus Berdasarkan Filipi 1:21 Serta Implikasinya Bagi Orang Percaya Masa Kini," T e o l o g i S a n c t u m do m i n e 3 No 1 (2018): 1-4, http://www.journals.ukitoraja.ac.id/index.php/kinaa/article/view/1053.

${ }^{28}$ Johanes Witoro, "Strategi Penginjilan Paulus Di Filipi Dalam Kitab Kisah Para Rasul 16 : 13-40

Relevansinya Bagi,” Jurnal Teologi Biblika 6, no. 2 (2021): 5, https://www.jurnal.stt-

biblika.ac.id/index.php/jtb/article/download/103/51.

${ }^{29}$ Tafsiran Utley, "Alkitab Sabda,"

https://alkitab.sabda.org/verse_commentary.php?book=50\&chapter=3\&verse $=7$.
} 
retoris, ${ }^{30}$ kemampuan ini juga akhirnya yang dipakai Paulus untuk berapologet mengenai iman Kristen menghadapi para cendekiawan-cendekiawan Yahudi dan Yunani pada saat itu. Selain itu kemampuanPaulus juga mengenal dunia Yunani dan menyaksikan ahli filsafat Stoa yang sinis, namun pertobatan Paulus menguras habis ide-ide keagamaan lama dan menggantikan dengan sesuai ajaran teologia yang lengkap. ${ }^{31}$ Secara logika, hal ini bukan perkara yang mudah jika tidak mengalami perubahan konsep berfikir yang radikal dari seorang Paulus ternyata hal ini diakibatkan oleh pertemuan Paulus secara pribadi dengan Kristus. Sebagai seorang yang sudah mengalami perjumpaan dengan Kristus, Paulus telah melepaskan keuntungankeuntungan (Yunani," $\varepsilon \varepsilon \rho \delta \eta$ kerdê", jamak) yang mungkin sudah diperoleh Paulus (5-6),

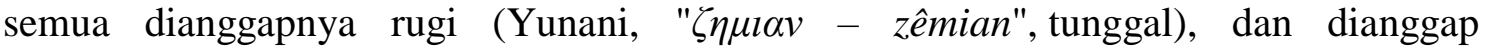
penghalang dan rasul Paulus dan harus belajar untuk meninggalkan semua keuntungankeuntungan tersebut. Kata, $\sigma \kappa v \beta \alpha \lambda \alpha$ (skubala) noun - accusative plural neuter dari kata

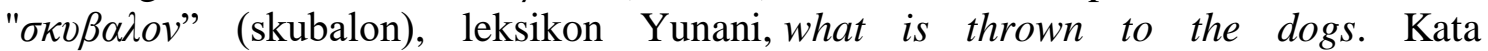

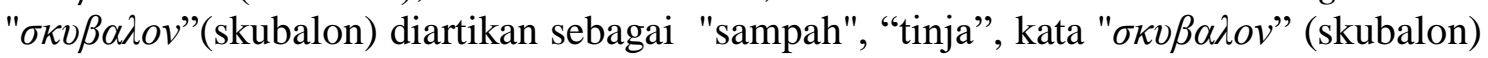

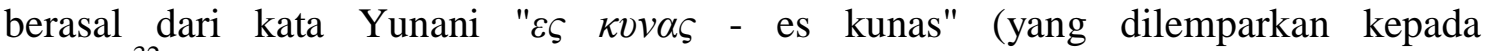
anjing). ${ }^{32}$ Kebanggaan-kebanggaan Paulus sebelum mengenal Kristus adalah disunat pada hari kedelapan, orangtua bukan dari orang kafir atau campuran melainkan berasal dari bangsa Israel asli, keturunan bangsa Israel (Fil 3:4-6), dari suku Benyamin sebagai suku yang dipilih menjadi raja pertama bangsa Israel, dididik dalam bahasa Ibrani dan mengetahui bahasa tersebut dengan baik dengan guru Gamaliel yang terkenal, memahami bahasa Yunani dan bahasa Aram yaitu bahasa yang dipakai di Palestina pada di zaman Yesus seorang Farisi menurut mazhab yang paling keras dalam agama Yahudi, tentang kegiatan ia adalah penganiaya jemaat yang paling giat, tidak bercacat mentaati hukum Taurat menurut ukuran Paulus, maka seorang Penginjil adalah orang yang melepaskan sesuatu agar memperoleh Kristus, dan ketika sesuatu yang dianggap keuntungan itu dilepaskan seperti melemparkan kepada anjing. Makna tersirat disini adalah, ketika seseorang sudah melepaskan sesuatu (kekayaan,kehormatan, kemuliaan, pekerjaan, asset-aset yang berlimpah) karena Kristus maka jikalau kebanggan masa lalu itu diambil kembali atau digunakan kembali akan berbahaya seperti mengambil sesuatu dari mulut anjing yang sedang memakan suatu kotoran atau sampah, jadi kriteria yang Pertama seorang Penginjil adalah membuang kebanggaan-kebanggan di masa lalu atau latarbelakang sebelum seseorang menjadi seorang Penginjil.

Paulus mengatakan bahwa apa yang didambakannya dan dikejarnya adalah pengenalan akan Kristus yang memberikan sukacita (sudah dan sedang) mencapai kemenangan. Ketika Paulus melepaskan segala sesuatu karena Kristus, Paulus menganggap itu sebuah kemenangan. ${ }^{33}$ Pernyataan Paulus ini menjadi hal yang kontradiktif, namun demikanlah Paulus memiliki pola yang berfikir ketika mengambil sikap atau keputusan menjadi penginjil.Paulus meninggalkan kebanggaan di masa lampau karena kebanggan itu tidak dapat dibandingkan dengan kebanggan dimasa yang

\footnotetext{
${ }^{30}$ Robinson Rimun, "Latar Belakang Hidup Dan Pendidikan Rabinik Paulus Dalam Kaitannya Dengan Perjumpaannya Dengan Kristus," PASCA: Jurnal Teologi dan Pendidikan Agama Kristen 15, no. 2 (2019): 1-8.

${ }^{31}$ M.Th Seri Damarwanti, SE, "Pandangan Rasul Paulus Tentang Jembatan Pengantar Injil. Kajian Misiologi Terhadap 1 Korintus 9:1-23," T e o l o g i S a n c t u $m$ d o m i ne (n.d.): 98.

32،AAlkitab Sabda," (YLSA), Yayasan Lembaga SABDA, 4657, (YLSA), Yayasan Lembaga SABDA.

${ }^{33}$ Mathew Hendry, Tafsiran Matthew Henry (Surat Galatia, Efesus, Filipi, Kolose, I \& II Tesalonika, I\&II Timoteus, Titus, Filemon, ed. Stevy W Tilaar Johny Tjia, Barry Van der School (Surabaya: Momentum, 2015), 310.
} 
akan datang yaitu pengharapan dalam Kristus, tentu tema pengharapan bukan sesuatu yang ilmiah dalam sudut pandang akademis dan rasio berfikir secara ilmihmaka hal ini berhubungan dengan masalah kerohanian atau spiritual. Ketika Paulus mengambil keputusan meninggalkan kebanggaan masa lalu, dalam surat-surat Paulus yang lain Paulus mengungkapkan bahwa Paulus bersukacita meskipun konsekuensi dari keputusan Paulus untuk menjadi pemberita Injil mengalami tantangan yang berat seperti penganiayaan, buronan negara dan menjadi musuh kelompok garis keras dari orang Yahudi pada zaman itu yang menganggap penganiayaan dan perlawanan kepada Injil adalah penyembahan yang benar kepada Allah untuk memurnikan pengajaran di Bait sucidari kekristenan.

Paulus tidak memberikan syarat-syarat, atau batasan-batasan yang diperlukan untuk mengukur kepuasannya tetpai Paulus hidup dalam keadaan itu, hal inilah yang memungkinkan Allah memakai orang ini secara efektif, inilah yang membuat pengaruh dirinya bersifat heroik. ${ }^{34}$ Tantangan yang dihadapi oleh Paulus saat menjadi seorang Farisi yang menekankan penyembahan yang benar kepada YHWH justru sekarang menjadi seteru Yahudi karena Injil dan kehilangan kesempatan menyembah Tuhan di Bait Suci yang dianggap sebagai tempat menyembah Allah yang benar dan tempat berdoa di saat itu.Namun dalam tugas pemberitaan Injil kehilangan status pemimpin agama Yahudi yang dialami oleh Paulus diterima dengan sukacita demi Kerajaan Allah memberi gambaran yang lebih jelas daripada yang dapat diberikan oleh penyembahan dan doa bahwa Allah lebih berharga daripada segalanya. ${ }^{35}$

\section{Melayani Dengan Konsep Augerah (Ayat 9)}

Mengalami anugerah Allah adalah melayani dengan tidak mengandalkan kompetensi-kompetensiyang bersifat sekuler.Doa Paulus yaitu "dan berada dalam Dia", ini adalah sebuah aorist passive subjunctive mengungkapkan doa Paulus yang terdalam adalah pembangunan tata bahasa favorit Paulus untuk orang percaya Ef 1:3,4,6,7,9,10bukan dengan kebenaran sendiri karena mentaati hukum Taurat tapi karena kasih karunia yaitu dengan kebenaran karena kepercayaan kepada Kristus yaitu iman dan pertobatan yang merupakan dua aspek mutlak dari respon umat manusia terhadap perjanjian baru (Mrk1:15; Kis 3:16,19; 20:21). Persekutuan dalam penderitaan-Nya adalah tema umum dari pengalaman orang Kristen di beberapa abad pertama sebagaimana dalam banyak masyarakat di dunia saat ini (Rom 8:17; 1Tes 3:3; 2Tim 3:12), menjadi serupa dengan Dia dalam kematian-Nya sebuah Present Passive Participle. Orang percaya harus mati bagi dosa dan diri sendiri dan hidup bagi Allah dan hidup sejati didahului oleh kematian terhadap kehidupan lama. ${ }^{36}$

Frasa "Supaya di dalam Dia" digambarkan seperti pembunuh yang berada dalam kota perlindungan aman dari penuntut balas (Bil 35:25) atau merujuk kepada keadaan di pengadilan, sehingga keadaan kita didapati berdamai dengan Dia. ${ }^{37}$ Dalam setiap tulisan Paulus konsep keselamatan Rasul Paulus bersifat teomorfistis, bertolak dari Allah, oleh

\footnotetext{
${ }^{34}$ Seri Damarwanti, SE, "Pandangan Rasul Paulus Tentang Jembatan Pengantar Injil. Kajian Misiologi Terhadap 1 Korintus 9:1-23."

${ }^{35}$ John Piper, Jadikan Segala Bangsa Bersukacita (Bandung: Lembaga Literature Baptis (LLB), 2003), 115.

36، Alkitab Sabda."

${ }^{37}$ Mathew Hendry, Tafsiran Matthew Henry (Surat Galatia, Efesus, Filipi, Kolose, I \& II Tesalonika, I\&II Timoteus, Titus, Filemon.
} 
Allah dan untuk Allah ${ }^{38}$ memenuhi tugas yang telah ditetapkan Allah bagi Paulus. Itulah sebabnya kita harus menginterpretasikan ide-ide Paulus berdasarkan keanekaragaman latarbelakangnya.Teologi Paulus memberi perhatian khusus pada manusia baru dalam Kristus,akibat dosa manusia mengalami status sebagai orang berdosa bukan karena melakukan tindakan dosa.Oleh karena itu, status yang harus dipulihkan dihadapan Allah dan membutuhkan anugerah dari Allah. ${ }^{39}$ Roh kudus memberikan kuasa kepada orang percaya untuk berani bersaksi melalui hidup dan bersaksi tentang Injil Tuhan sehingga orang percaya tidak melayani dengan kekuatan sendiri tetap kuasa. ${ }^{40}$ Oleh karena itu dalam melaksanakan Amanat Agung diperlukan visi yang ditekankan adalah pemuridan bukan sekedar mengambil keputusan dari tindakan awal ketika seseorang mendengarkan Injil ${ }^{41}$, sehingga pertumbuhan dan misi adalah penginjilan yang mencari untuk memuridkan ${ }^{42}$ sehingga dalam pelayanan Paulus, Paulus memberitakan Injil kepada orang Yahudi dan non Yahudi. Prinsip rasul Paulus dalam memberitakan Injil yaitu ia tidak memandang latar belakang dan kebudayaan orang dalam penginjilannya. ${ }^{43}$

\section{Akurasi Yang Tinggi Memahami Konsep Kristologi (10-11)}

Kuasa kematian dan kebangkitan Kristus berbicara tentang penyangkalan diri

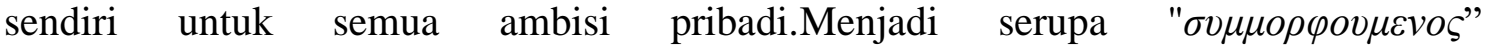
(summorphoumenos) dalam bentuk present passive participledalam kematian-Nya (ayat 10) mengandung arti bahwa pengalaman tersebut sebagai pengalaman mati terhadap diri sendiri dan hidup bagi Allah.Cara Tuhan menyelamatkan orang yang berdosa adalah kontak dengan Injil sehingga membawa mereka kepada iman. ${ }^{44}$ Serupa dengan Kristus adalah kematian terhadap segala keinginan dan ambisi rasul Paulus dan mengambil bagian dalam penderitaanNya. Paulus selalu merindukan agar semakin meningkat dalam pengenalan akan Kristus, jadi ada progresif pengenalan Tuhan menjadi orang Kristen.Ayat 11 adalah suatu Kalimat third class conditional yang berarti kemungkinan tindakan di masa depan maka ayat 11 harus ditafsirkan dalam terang ayat. Frasa "aku akhirnya beroleh"di sini sekali lagi adalah model dialektis atau paradoks dari teologia Paulus. Paulus tahu bahwa ia seorang Kristen dan bahwa sebagaimana Kristus dibangkitkan oleh Roh, ia juga akan dibangkitkan (Rom 8:9-11)tidak hanya peristiwa di masa lalu tapi proses yang berkelanjutan.Frasa ini tidak mengartikan keraguan tentang keselamatan, tetapi kerendahan hati dari seorang Paulus. ${ }^{45}$ Paulus memandang hal rohani dalam hal ini Sorga sebagai kebahagiaannya (ay. 11).Kebahagiaan sorgawi disebut kebangkitan dari antara orang mati dimasa yang akan datang, namun kebahagiaan orang kristen belumlah sempurna sampai kepada kebangkitan semua orang mati pada akhir zaman, ketika jiwa dan tubuh akan dimuliakan bersama-sama, Anastasis terkadang

\footnotetext{
${ }^{38}$ Sekolah Tinggi and Teologi Jaffray, "Keselamatan Dalam Konsep Rasul Paulus," Integritas 1, no. 1 (2019): 26, http://journal.sttjaffrayjakarta.ac.id/index.php/JI.

${ }^{39}$ Louis Berkoff, Teologi Sistematika - Doktrin Manusia (Surabaya: Momentum, 2006), 163.

${ }^{40}$ Ruat Diana and Ayu Rotama Silitonga, "Konsep Alkitab Tentang Peran Roh Kudus Dalam

Penginjilan,” Jurnal Teologi Praktika (Sekolah Tinggi Teologi Tenggarong, 2021).

${ }^{41}$ Paulus Kunto Baskoro, "Tinjauan Dampak Metode Penginjilan 'Evangelism Explosion' Bagi

Pertumbuhan Jemaat Lokal,” Charistheo: Jurnal Teologi dan Pendidikan Agama Kristen 1, no. 1 (2021):

77, https://e-journal.anugrah.ac.id/index.php/JCH/article/view/5/6.

${ }^{42}$ Dorce Sondopen, "Relasi Antara Penginjilan Dan Pemuridan Untuk Pertumbuhan Gereja," Excelsis Deo: Jurnal Teologi, Misiologi, dan Pendidikan 3, no. 2 (2019): 104.

${ }^{43}$ Magdalena and Tampenawas, "Memberitakan Injil Sebagai Suatu Panggilan Hamba Tuhan Dalam Perspektif Kisah Para Rasul 16:4-10."

${ }^{44}$ Packer, Penginjilan Dan Kedaulatan Allah, Terjemahan Helda Siahaan.

${ }^{45}$ Utley, "Alkitab Sabda."
} 
diterjemahkan masa depan. Inilah yang dinanti-nantikan oleh Rasul Paulus dan ingin dicapainya. Akan terjadi kebangkitan orang-orang fasik, yang akan bangkit untuk mengalami kehinaan dan kengerian yang kekal. Kita harus menjaga agar terhindar dari hal ini. Sebaliknya, kebangkitan penuh sukacita dan kemuliaan orang-orang kudus disebut kebangkitan kat' exochēn - penuh kebesaran, (Mathew Henry). ${ }^{46}$

Dalam ayat ini mengenal lebih kepada perubahan cara dan pola hidup Paulus dari kehidupan yang lama sehingga Paulus memiliki karakter yang dikehendaki Kristus sehingga hal-hal yang bersifat duniawi dapat dipadamkan dan hidup dalam kebenaran. ${ }^{47}$ Kuasa kematian dan kebangkitan Kristus berbicara tentang kerelaan mengalami kesulitan dan penderitaan yang dialami oleh Tuhan Yesus ketika melayani.Sebaliknya, menurut Hutahaean reduksi terhadap makna dan karya Kristus dengan berbagai cara termasuk dalam praksis pelayanan, cepat atau lambat akan nyata sebagai ilusi belaka. ${ }^{48}$ Makna memperoleh kebangkitan dalam Kristus merujuk kepada masa penghakiman dimasa yang akan datang yaitu bahwa orang-orang yang mati dalam Kristus akan mengalami kehidupan yang kekal dan bukan kematian yang kedua (neraka) oleh karena pembenaran bukan karena kebenaran diri sendiri. ${ }^{49}$

\section{Konsisten kepada Orientasi "Panggilan Sorgawi" (12-14)}

Panggilan sorgawai adalah suatu panggilan yang tidak dapat dihindari ataupun ditolak.Pada ayat 12tujuan hidup dari Paulus yang dapat diartikan dengan secara sederhana (tetapi aku terus maju dengan susah payah kalau-kalau aku dapat juga menangkapnya). $\kappa \alpha \tau \alpha \lambda \alpha \beta \omega$ - katalabô verb (second aorist active subjunctive - first person singular), dari kata $\kappa \alpha \tau \alpha \lambda \alpha \mu \beta \alpha v \omega$ (katalambanô) to take eagerly, seize, possess, apprehend, attain, come upon, comprehend, find, obtain, perceive. Katalambani dalam papirus dipakai untuk tanah yang diambil oleh para penjajah ungkapan untuk apa yang dialami oleh Paulus ketika ditangkap oleh Kristus di jalan menuju ke Damsyik. Allah memiliki rencana melalui pertobatan Paulus, dan rencana Allah dalam dirinya diinginkan oleh Paulus untuk direalisasikan oleh Allah. Kata " $\varepsilon \varphi \omega-e p h$ hô" berarti "karena" yang dengan demikian akan menekankan alasan bukan sasaran dari jerih payah Paulus. Paulus yang ditangkap seperti seorang Polisi menangkap seseorang sehingga tidak bisa melarikan diri. Ketika seorang Polisi menangkap seseorang maka proses yang akan dialami adalah proses pengadilan untuk dihukum, tetapi Kristus menangkap Paulus dengan tujuan agar Paulus tidak dihukum dan diadili karena status manusia yang berdosa dimasa yang akan datang, ${ }^{50}$ demikianlah Paulus yang sudah ditangkap oleh Allah berusaha dalam panggilan Kristus juga berusaha untuk menangkap setiap maksud-maksud Tuhan dalam panggilan yang dikerjakan oleh Paulus untuk memberitakan Injil kepada bangsa-bangsa yang tidak mengenal Tuhan. Ketika seseorang mendapatkan panggilan dalam mengerjakan pelayanan ini adalah sebuah proses. Paulus menyadari bahwa dirinya tidak sempurna dan sedang diuji.Dari sudut pandang manusia, kita dapat menilai Paulus sudah mencapai tingkat komitmen yang

\footnotetext{
${ }^{46}$ Mathew Hendry, "Tafsiran," https://alkitab.sabda.org/commentary.php.

${ }^{47}$ Mathew Hendry, Tafsiran Matthew Henry (Surat Galatia, Efesus, Filipi, Kolose, I \& II Tesalonika, I\&II Timoteus, Titus, Filemon.

${ }^{48}$ Hasahatan Hutahaean, "Kristologi Miring; Khotbah Yang Lancung," in KRISTOLOGI MIRING:

Respons Historis, Doktrinal, Dan Apologetika Kristen, ed. Stenly R. Paparang, Pangeran Manurung, and Elia Tambunan (Surabaya: Bible Culture Study, 2020), 259.

${ }^{49}$ Mathew Hendry, Tafsiran Matthew Henry (Surat Galatia, Efesus, Filipi, Kolose, I \& II Tesalonika, I\&II Timoteus, Titus, Filemon.

${ }^{50}$ Ibid.
} 
tinggi menjadi pengikut Kristus, namun Paulus tidak segan-segan mengakui dan menyadari bahwa proses dalam mengikut Kristus masih terdapat banyak kekurangan dalam hal kewajiban, anugerah dan penghiburan. ${ }^{51}$

Panggilan sorgawi adalah melakukan sebuah visi dan menyelesaikan sampai akhir hidupsemua proses yang mengikuti pencapaian visi. Pada ayat 13 rasul Paulus menjelaskan kembali bahwa orang Kristen harus menghancurkan sikap berpuas diri dan terus berjuang sekuat tenaga sampai akhir hidup seperti dalam sebuah pertandingan dan tidak memusatkan kepada diri sendiri atau kepada orang lain tetapi kepada tujuan ( $\sigma \kappa о \pi о v^{\prime \prime s k o p o n ") ~ d a r i ~ k a t a ~} \sigma \kappa о \pi \varepsilon \omega ~ " s k o p e \hat{o "(m e m a n d a n g ~ k e p a d a) ~ s e s u a t u ~ s e b a g a i ~}$ sasaran perhatian penuh, apabila pandangan beralih atau menyimpang maka dapat berakibat fatal dan berbahaya. Pandangan tersebut adalah kepada hadiah yaitu panggilan sorgawi dan dilakukan dengan segenap hati menjauhi prestasi diri sendiri tetapi di dalam Kristus memperoleh pencapaian-pencapaian rohani.Orang percaya harus terus menerus mengejar tujuan dari keselamatan akhir, sebab masih hidup dalam zaman sekarang ini (ayat 12-14) ${ }^{52}$, yaitu memberitakan keselamatan, tetap berada dalam keselamatan sampai akhir.Mengarahkan diri kepada apa yang dihadapanku (ayat 14) ini merupakan gambaran seorang yang mengikuti pertandingan lari di garis yang sudah ditentukan untuk seorang pelari untuk mendapatkan hadiah. Tujuan ( $\sigma \kappa о \pi o v$-skopon)

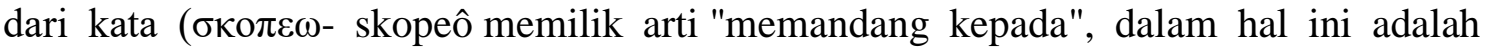
hadiah sehingga membuat pelari tidak memperdulikan keadaan disekeliling tetapi fokus mempersiapkan segala potensi yang ada untuk sampai kepada tujuan atau finish.Kalau berbicara tentang aturan yang harus dilakukan untuk mencapai sebuah panggilan, maka tidak dapat dilepaskan dari sebuah komitmen untuk terus setia mengerjakan visi. ${ }^{53}$ Oleh karena itu, dalam mengerjakan panggilan sorgawi, Paulus dengan rendah hati dan mengetahui segala konsekuensi yang akan dialami dalam mengerjakan panggilan sorgawi, namun

Mengerjakan panggilan Sorgawi adalah bertahan dalam tantangan dengan mengikuti aturan yang ditentukan.Paulus mengerjakan panggilan sorgawi ini dengan rendah hati, konsisten, berpegang teguh kepada integritas sebagai pengikut Kristus. ${ }^{54}$ Dalam konteks saat ini, tentu menjadi penginjil memiliki tantangan untuk setiap zaman.Pemberitaan Injil akan selalu mendapatkan perlawanan misalnya dalam konteks Indonesia, beberapa orang berpendapat Injil sebagai sumber konflik di Indonesia, tetapi Injil asalnya adalah kabar sukacita tentang kasih dan pengampunan Tuhan. ${ }^{55}$ Dalam panggilan sebagairasul untuk bangsa-bangsa non Yahudi (lintas budaya), Paulus menghadapi semua tantangan dan mengalami penderitaan dalam mengerjakan Amanat Agung Tuhan Yesus, oleh karena itu dalam penjangkauan yang dilakukan oleh rasul Paulus, Paulus melakukan strategi pendekatan kontekstual dalam pemberitaan Injil.Amanat Agung menjadi dasar perintah yang berotoritas penuh untuk melakukan penjangkauan penginjilan lintas budaya, yang dapat dilakukan dengan metode kontekstual seperti yang Paulus lakukan dalam pelayanan penginjilanya, ia masuk

\footnotetext{
${ }^{51}$ Ibid.

${ }^{52}$ Packer, Penginjilan Dan Kedaulatan Allah, Terjemahan Helda Siahaan.

${ }^{53}$ Hasahatan Hutahaean, Pelayan Tuhan Di Gereja Dan Masyarakat (Luwuk: Pustaka Star's Lub, 2020).

${ }^{54}$ Tri Hananto and Erni M.C. Efruan, "Model Kemartiran Dalam Penginjilan Rasul Paulus Berdasarkan

Kisah Para Rasul Terhadap Kelompok Kabar Baik Di Malang," Missio Ecclesiae 10, no. 1 (2021): 13.

${ }^{55}$ Ninla Elmawati Falabiba et al., "Urgensi Penginjilan Sebagai Tanggungjawab Gereja," Paper

Knowledge . Toward a Media History of Documents 5, no. 2 (2014): 7.
} 
dalam segala konteks kebudayaan ${ }^{56}$ sehingga Injil dapat didengar oleh semua suku bangsa dan Bahasa secara khusus di Indonesia.Gereja baik secara personal, komunal dan institusional harus melakukan penginjilan karena merupakan hal yang sangat penting sebagai Amanat Agung Tuhan Yesus, maka Gereja harus memperlengkapi diri dengan semangat yang tinggi, kompetensi, keperbergantungan kepada pekerjaan Roh Kudus, motivasi yang murni dalam memberitakan Injil baik melalui perkataan dan perbuatan. ${ }^{57}$ Oleh karena itu penyerahan total kepada Kristus, konsistensi, daya tahan, prediktabilitas, kasih kepada orang yang belum mengalami Injil, upaya untuk memimpin kepada Tuhan tanpa syarat tanpa akhir, menjauhkan kemunafikan tetapi kejujuran dan kasih karunia keselamatan Allah dari orang yangtelah diubahkan kepada orang-orang yang mendengarkan Inji1 ${ }^{58}$ dalam mengerjakan panggilan sorgawi.

\section{KESIMPULAN}

Kekristenan tanpa Kristus adalah mati karena yang menjadi pusat kekristenan itu sendiri adalah Yesus Kristus. Kekristenan adalah pengenalan akan Yesus Kristus, siapa, mengapa, dan apa yang telah dilakukan Yesus ketika menjadi manusia. Dunia ini adalah tempat pelayanan yang dikerjakan oleh Tuhan Yesus untuk saat yang ditentukan ketika Yesus menjadi manusia. Ketika Yesus menyelesaikankarya penyelamatan di kayu salib, maka tugas itu diberikan kepada para pengikutNya yang disebut dengan Amanat Agung. Amanat Agung tidak dapat dikerjakan tanpa pengutusan, pengutusan tidak dapat dikerjakan tanpa penginjilan, dan tanpa para penginjil tidak ada yang akan berbicara untuk menyampaikan Injil, oleh karena itu mempersiapkan para Penginjil harus dibekali dengan kesiapan hati dan pola fikir para penginjil yang telah mengalami pembaharuan dalam segala aspek dan konsep para penginjil yaitu visioner, pelayanan dengan konsep anugerah, akurasi pemahaman konsep kristologi, konsistensidalam mengerjakan panggilan sehingga ketika mengerjakan tugas pemberitaan Injil maka apa yang menjadi standard kriteria seorang Penginjil akan dikerjakan di ladang misi.

\section{DAFTAR PUSTAKA}

Baskoro, Paulus Kunto. “Tinjauan Dampak Metode Penginjilan 'Evangelism Explosion' Bagi Pertumbuhan Jemaat Lokal.” Charistheo: Jurnal Teologi dan Pendidikan Agama Kristen 1, no. 1 (2021): 70-89. https://ejournal.anugrah.ac.id/index.php/JCH/article/view/5/6.

Berkoff, Louis. Teologi Sistematika - Doktrin Manusia. Surabaya: Momentum, 2006. BPS. "Penduduk Menurut Wilayah Dan Agama Yang Dianut." Badan Pusat Statistik. Last modified 2020. http://sp2010.bps.go.id/index.php/site/.

Diana, Ruat, and Ayu Rotama Silitonga. "Konsep Alkitab Tentang Peran Roh Kudus Dalam Penginjilan.” Jurnal Teologi Praktika. Sekolah Tinggi Teologi Tenggarong, 2021.

Fernando, Ajith. Allah Tritunggal Dan Misi. Jakarta: Yayasan Komunikasi Bina Kasih (YKBK), 2008.

\footnotetext{
${ }^{56}$ Jhon Leonardo Presley Purba and Sari Saptorini, "Metode Penginjilan Paulus Dalam Perspektif 1 Korintus 9:19-23 Terhadap Masyarakat Multikultural Dan Implikasinya Terhadap Penginjilan Di Indonesia," Veritas Lux Mea (Jurnal Teologi dan Pendidikan Kristen) 2, no. 2 (2020): 182, https://jurnal.sttkn.ac.id/index.php/Veritas/article/view/91.

${ }^{57}$ Yohanes Joko Saptono, "Pentingnya Penginjilan Dalam Pertumbuhan Gereja," DIEGESIS: Jurnal Teologi Kharismatika 2, no. 1 (2019): 22, https://ojs.sttrealbatam.ac.id/index.php/diegesis/article/view/46. ${ }^{58}$ Djuwansah Suhendro P Stephanus, "Mengajarkan Penginjilan Sebagai Gaya Hidup Orang Percaya," REDOMINATE: Jurnal Teologi dan Pendidikan Kristiani 1, no. 1 (2019): 16.
} 
Goldworthy, Graeme. Preaching The Whole Bible As Christian Scripture,. Inggris: IVP, 2003.

Graham, Billy. Beritakan Injil,. Bandung: LLB (Lembaga Literature Baptis), 2001.

Hamzah, Amir. Metode Penelitian Kepustakaan. Revisi. Malang: Literasi Nusantara, 2020.

Hananto, Tri, and Erni M.C. Efruan. "Model Kemartiran Dalam Penginjilan Rasul Paulus Berdasarkan Kisah Para Rasul Terhadap Kelompok Kabar Baik Di Malang." Missio Ecclesiae 10, no. 1 (2021): 1-18.

Hendricks, Howard. G. Beritakan Injil Dengan Kasih. Jakarta: BPK Gunung Mulia, 2000.

Hutagalung, Stimson. Strategi Pelayanan Dan Penginjilan,. Medan: Yayasan Kita Menulis, 2021.

Hutahaean, Hasahatan. "Kristologi Miring; Khotbah Yang Lancung." In KRISTOLOGI MIRING: Respons Historis, Doktrinal, Dan Apologetika Kristen, edited by Stenly R. Paparang, Pangeran Manurung, and Elia Tambunan, 255-274. Surabaya: Bible Culture Study, 2020.

—. Pelayan Tuhan Di Gereja Dan Masyarakat. Luwuk: Pustaka Star's Lub, 2020. . "Tantangan Teologi Agama-Agama: Suatu Diskursus Model.” KURIOS (Jurnal Teologi dan Pendidikan Agama Kristen) 6, no. 2 (2020): 255-270.

Ikbar, Yanuar. Metode Penelitian Sosial Kualitatif. Bandung: Refika Aditama, 2014. International, Dynamic Churches. Penginjilan Yang Dinamis. Bandung: Kalam Hidup, 2014.

Jhon Marthin Elizon Damanik, Binsar Jonathan Pakpahan. "Membuang Undi Menemukan Pemimpin: Analisis Plus Minus Sistem Undi Pemilihan Pemimpin Dalam Kisah Raja Saul.” Jurnal Abdiel IV (2020): 212.

Klumpenhower., Jack. Kenalkan Yesus Pada Mereka. Surabaya: Momentum, 2014. Lee, Witness. Memberitakan Injil Dalam Jalan Hayat. Jakarta: Yaperin, 2021. Magdalena, Erna, and Alfons Renaldo Tampenawas. "Memberitakan Injil Sebagai Suatu Panggilan Hamba Tuhan Dalam Perspektif Kisah Para Rasul 16:4-10." XAIRETE: Jurnal Teologi dan Pendidikan Kristiani 1, no. 1 (2021): 52-64. http://e-journal.sttkai.ac.id/index.php/xairete/index.

Mangentang, Matheus, and Tony Salurante. "MEMBACA KONSEP KASIH DALAM INJIL YOHANES MENGGUNAKAN LENSA HERMENEUTIK MISIONAL." Phronesis: Jurnal Teologi dan Misi 4, no. 1 (2021): 1-13.

Manurung, Kosma. "Efektivitas Misi Penginjilan Dalam Meningkatkan Pertumbuhan Gereja." DUNAMIS: Jurnal Teologi dan Pendidikan Kristiani 4, no. 2 (2020): 225-233.

Mathew Hendry. "Tafsiran.” https://alkitab.sabda.org/commentary.php.

—. Tafsiran Matthew Henry (Surat Galatia, Efesus, Filipi, Kolose, I \& II Tesalonika, I\&II Timoteus, Titus, Filemon. Edited by Stevy W Tilaar Johny Tjia, Barry Van der School. Surabaya: Momentum, 2015.

Ninla Elmawati Falabiba, Wisnu Anggaran, Affiifi. Mayssara A. Abo Hassanin Supervised, B.B Wiyono, Ninla Elmawati Falabiba, Yong Jun Zhang, Yong Li, and Xu Chen. "Urgensi Penginjilan Sebagai Tanggungjawab Gereja." Paper Knowledge . Toward a Media History of Documents 5, no. 2 (2014): 40-51.

Packer, J.I. Penginjilan Dan Kedaulatan Allah, Terjemahan Helda Siahaan. Edited by Hendry Ongkowidjojo. Surabaya: Momentum, 2010.

—. "Penginjilan Dan Kedaulatan Allah." Surabaya: Momentum, 2003. 
Paembonan, Yafet M. "Memahami Tantangan Teologi Pluralisme Dan Teologi Pembebasan.” Jurnal Teologi Berita Hidup 2, no. 1 (2019): 48-59.

Panggua, Grace Maya. "Hidup Dan Mati Studi Eksegetis Mengenai Maksud Perkataan Paulus Berdasarkan Filipi 1:21 Serta Implikasinya Bagi Orang Percaya Masa Kini." T e o l o g i S a n c t u m d o m i n e 3 No 1 (2018): 1-17. http://www.journals.ukitoraja.ac.id/index.php/kinaa/article/view/1053.

Piper, John. Jadikan Segala Bangsa Bersukacita. Bandung: Lembaga Literature Baptis (LLB), 2003.

Purba, Jhon Leonardo Presley, and Sari Saptorini. "Metode Penginjilan Paulus Dalam Perspektif 1 Korintus 9:19-23 Terhadap Masyarakat Multikultural Dan Implikasinya Terhadap Penginjilan Di Indonesia." Veritas Lux Mea (Jurnal Teologi dan Pendidikan Kristen) 2, no. 2 (2020): 171-184. https://jurnal.sttkn.ac.id/index.php/Veritas/article/view/91.

Rimun, Robinson. "Latar Belakang Hidup Dan Pendidikan Rabinik Paulus Dalam Kaitannya Dengan Perjumpaannya Dengan Kristus." PASCA: Jurnal Teologi dan Pendidikan Agama Kristen 15, no. 2 (2019): 1-8.

Santosa, Eka Budhi. "Studi Teologis-Historis Kebangkitan Yesus: Suatu Jawaban Terhadap Isu Makam Talpiot.” Antusias: Jurnal Teologi dan Pelayanan 2, no. 3 (2013): 84-99.

Saptono, Yohanes Joko. "Pentingnya Penginjilan Dalam Pertumbuhan Gereja." DIEGESIS: Jurnal Teologi Kharismatika 2, no. 1 (2019): 12-24. https://ojs.sttrealbatam.ac.id/index.php/diegesis/article/view/46.

Seri Damarwanti, SE, M.Th. "Pandangan Rasul Paulus Tentang Jembatan Pengantar Injil. Kajian Misiologi Terhadap 1 Korintus 9:1-23." T e o l o g i S a n c t u m do mi ne (n.d.): 1-23.

Sills, M David. Panggilan Misi; Menemukan Tempat Anda Dalam Rancangan Allah Bagi Dunia Ini. Momentum, 2011.

Sondopen, Dorce. "Relasi Antara Penginjilan Dan Pemuridan Untuk Pertumbuhan Gereja." Excelsis Deo: Jurnal Teologi, Misiologi, dan Pendidikan 3, no. 2 (2019): 95-105.

Spurgeon, Charles H. The Soul Winner. Yogyakarta: Andi, 2008.

Stephanus, Djuwansah Suhendro P. "Mengajarkan Penginjilan Sebagai Gaya Hidup Orang Percaya.” REDOMINATE: Jurnal Teologi dan Pendidikan Kristiani 1, no. 1 (2019): 12-22.

Stott, John. Evangelical Truth- A Personal Plea for Unity, Integrity And Faithfullness. London: Langham Creative Projects, 2012.

Tinggi, Sekolah, and Teologi Jaffray. "Keselamatan Dalam Konsep Rasul Paulus." Integritas 1, no. 1 (2019): 15-28. http://journal.sttjaffrayjakarta.ac.id/index.php/JI.

Tong, Stephen. Hati Yang Terbakar. Momentum, 2007.

Utley, Tafsiran. "Alkitab Sabda." https://alkitab.sabda.org/verse_commentary.php?book=50\&chapter=3\&verse=7.

Waharman, Made Nopen Supriadi, Yesri Talan. "Kajian Biblika Prinsip Hidup Berpadanan Dengan Injil Kristus Berdasarkan Filipi 1: 27-30.” Phronesis: Jurnal teologi dan Misi IV no 1 (2021).

Witoro, Johanes. "Strategi Penginjilan Paulus Di Filipi Dalam Kitab Kisah Para Rasul 16 : 13-40 Relevansinya Bagi." Jurnal Teologi Biblika 6, no. 2 (2021): 3-12. https://www.jurnal.stt-biblika.ac.id/index.php/jtb/article/download/103/51.

"Alkitab Sabda." (YLSA), Yayasan Lembaga SABDA. (YLSA), Yayasan Lembaga 